\title{
SPATIAL AND TEMPORAL VARIABILITY OF BRONCHIECTASIS CASES IN SILESIAN VOIVODESHIP IN 2006-2010
}

\section{EWA NIEWIADOMSKA ${ }^{1}$, MALGORZATA KOWALSKA², and JAN E. ZEJDA ${ }^{2}$}

\author{
Medical University of Silesia, Katowice, Poland \\ ${ }^{1}$ School of Public Health in Bytom, Department of Epidemiology and Biostatistics \\ ${ }^{2}$ School of Medicine in Katowice, Department of Epidemiology
}

\begin{abstract}
Objectives: Reports on an increasing number of hospitalizations in other European countries and the lack of epidemiological data on the prevalence of bronchiectasis in Poland constituted motivation for the authors to investigate temporal changes of the registered incidence and hospitalization due to bronchiectasis in Silesian voivodeship, and to evaluate spatial variability of the disease in the study region. Material and Methods: The study is a descriptive epidemiological project. Temporal and spatial variability of coefficients describing numbers of newly diagnosed cases and first time hospitalizations due to bronchiectasis (code J47 according to International Statistical Classification of Diseases and Related Health Problems, 10th revision (ICD-10)) were evaluated based on the registered data available from the National Health Found (2006-2010) and the data from MZ/Szp-11 reports (2000-2011). The data concerned adults aged $\geq 19$ years, inhabitants of Silesian voivodeship. Maps of incidence or hospitalization rates due to bronchiectasis were constructed by the use of a geographical information system ArcGIS. Results: The obtained results show a stable trend of reported new diseases, whereas the number of first time hospitalizations is increasing. Values of the standardized incidence were 19.9-25.1/100 000 inhabitants, and values of the standardized first-time hospitalization were 1.2-2.9/100 000 inhabitants. The reported rates of bronchiectasis indicate significant spatial differences in epidemiological situation in the study region. Conclusions: The findings showed territorial variability of the incidence and hospitalization of bronchiectasis recorded in Silesian voivodeship. The observed variability might result from regional differences in the availability of specialized medical services.
\end{abstract}

Key words:

Maps, Descriptive study, Incidence rate, Cases of bronchiectasis, Hospitalization rate, Spatial epidemiology

\section{INTRODUCTION}

Bronchiectasis (code J47 according to the International Statistical Classification of Diseases and Related Health Problems, 10th revision (ICD-10)) is a chronic respiratory disease characterized by irreversible dilatation of bronchi and/or bronchioles associated with repeated infections or other factors impairing lung function such as foreign body, tumour, etc. [1-3]. The most often mentioned risk factors include exposure to toxic gases and irritating substances in the workplace [2]. Deficiency of $\alpha_{1}$-antytrypsin and occurrence of cystic fibrosis [2,4] are the most frequently described genetic factors. However, in almost $50 \%$ of the diagnosed cases the cause of the disease remains unknown [5].

According to the report, the European Lung White Book, accurate estimates of the prevalence of

Received: April 22, 2015. Accepted: October 5, 2015

Corresponding author: E. Niewiadomska, Medical University of Silesia, School of Public Health in Bytom, Department of Epidemiology and Biostatistics, Piekarska 18, 41-902 Bytom, Poland (e-mail: e.j.niewiadomska@gmail.com). 
bronchiectasis are unknown. Published data suggest that the incidence rate may vary between $0.5 / 100000$ inhabitants and 25/100 000 inhabitants [5-7]. Higher values of the incidence are observed in elderly population, people aged $>65$ years. Data concerning population aged $>75$ years in the United States suggest that the incidence rate in 2005 was close to 272/100 000 inhabitants [6]. Also American observations have revealed a significant increase in the incidence rates over the period 2000-2007, by $8.74 \%$ per year $(95 \%$ confidence interval (CI): $7.7-$ $9.79 \%$ ), in the population $>65$ years [7].

Some data obtained in the European countries show that bronchiectasis is rather a rare disease. In Finland, the prevalence rate was about $0.5 / 100000$ inhabitants in 1998 [5]. Results of German study have confirmed that the average standardized rate of hospitalization due to bronchiectasis in the years 2005-2011 was about 1.8/100 000 inhabitants [8].

According to the data quoted by the European Lung White Book, the largest value of the standardized mortality rate due to bronchiectasis was observed in Great Britain (1.18/100 000 inhabitants), in Hungary (1.31/100 000 inhabitants) and in Ireland (0.99/100 000 inhabitants). In Poland, the value of mortality rate was relatively low: 0.03/100 000 inhabitants [5].

An important aspect of bronchiectasis is the question of high direct and indirect costs related to its treatment, despite the small group of patients suffering from the disease. According to the estimates by the Thoracic Lung Association, the annual cost related to the treatment and premature mortality due to bronchiectasis in the USA in 2011 was about 1.4 billion USD and it was higher than the annual cost of many other chronic diseases [6].

Because of the apparent lack of data on the occurrence of bronchiectasis we decided to estimate the registered incidence and hospitalization rates of the disease in Silesian voivodeship, and to evaluate their temporal and spatial variability.

\section{MATERIAL AND METHODS}

The paper describes results of a descriptive epidemiological study involving adults, residents of Silesian voivodeship at the age of $\geq 19$ years, who were diagnosed with bronchiectasis (code J47, ICD-10) over the years 2000-2011. Silesian voivodeship, one of 16 voivodeships in Poland, is located in the southern part of the country. The number of inhabitants of Silesia region in 2010 amounted to 4635882 (12.1\% of the Polish population) with either compensated number of women (2 $401708,12.2 \%)$ and men $(2234174,12.1 \%)$. The area is highly urbanized and industrialized.

The number of new cases as well as first-time hospitalizations in 2006-2010 was obtained from the database of persons entitled to health care benefits called the Central List of the Insured and kept by the National Health Found (Narodowy Fundusz Zdrowia - NFZ), Katowice Department (Poland) on the basis of the act on Universal Health Insurance [9]. The NFZ data on bronchiectasis cases (as well as on other diseases) are updated annually. The database has a centralized nature and updates come from hospitals and other medical units interested in bronchiectasis and other respiratory diseases treatment.

The database contains all records of bronchiectasis as a primary diagnosis with anonymous demographic data: date of birth, gender, residence area and data on the treatment process: main diagnosis, date of the first diagnosis of the disease, date of first-time hospitalization and date of death. Data describing the cause of death of people with a diagnosis of bronchiectasis are not accessible because of the method of collecting and updating data by NFZ.

Data on the number of total hospitalizations due to bronchiectasis in 2000-2011 were acquired from the statistical hospital report cards (MZ/Szp-11) available from the Silesian voivodeship office in Katowice.

Demographic structure of the subjects was described by the number and relative frequency of patients, according 
to gender in the following aged groups: 19-34 years, $35-54$ years, 55-64 years, and $\geq 65$ years, in each year of reporting.

\section{Statistics}

Assessment of epidemiological situation with respect to bronchiectasis in the total population of Silesian voivodeship and in its local administrative units (Nomenclature of Territorial Units for Statistics - NTS-4) was performed by calculating crude incidence (newly reported cases) and first-time hospitalization rates, per 100000 of inhabitants aged $\geq 19$ years. Next, the rates were standardized using world standard population.

Crude rates of hospitalizations were obtained for each year and were presented as rates per 100000 inhabitants.

The incidence, first time hospitalization and hospitalization rates of bronchiectasis were subsequently linked with the maps of Silesian voivodeship in a form of mean values calculated for the study periods. Such a procedure revealed territorial variability of the epidemiological situation of the disease in the study region. The maps were constructed by the use of a geographical information system ArcGIS 9.2.

Statistical analyses were performed using procedures available in the $\mathrm{R}$ package v.2.11.1 (GNU General
Public License (GNU GPL)). Methods of descriptive statistics were applied to the analysis of temporal variability of the incidence and hospitalization rates. Data were presented for women and men separately in the 5-year age groups. Additionally, an association between the incidence and socio-economic status of inhabitants such as: unemployment rate, average salary, number of hospital beds, number of physicians as published by the Central Statistical Office of Poland [10] in each district (in Polish: powiat) of Silesian voivodeship were evaluated using the Spearman's correlation. Compatibility of the variables with the normal distribution was examined by means of the Shapiro-Wilk test. Interpretation of statistical significance was based on the criterion $\mathrm{p}<0.05$.

\section{RESULTS}

The results presented in Table 1 show that the number of new cases of bronchiectasis in the study population was stable over the study period. We observed a slow decline in the number of deaths among the patients with diagnosed bronchiectasis, in 2006 the percentage was twice as high as in 2010 (16\% and $6.8 \%$, respectively).

The average age at first-time diagnosis in subsequent years was 56.7-60.1 years, and at the time of death it

Table 1. Bronchiectasis (code J47, ICD-10) in the adults > 19 years, Silesian voivodeship, 2006-2010

\begin{tabular}{|c|c|c|c|c|c|c|}
\hline \multirow{2}{*}{ Variable } & \multicolumn{6}{|c|}{ Bronchiectasis in subsequent years } \\
\hline & 2006 & 2007 & 2008 & 2009 & 2010 & total \\
\hline Cases (total) [n] & 1382 & 1777 & 1647 & 1751 & 1603 & 8160 \\
\hline First-time outpatient visits [n (\%)] & $1307(94.6)$ & $1675(94.3)$ & $1496(90.8)$ & $1567(89.5)$ & $1429(89.1)$ & $7474(91.6)$ \\
\hline First-time hospitalizations [n (\%)] & $75(5.4)$ & $102(5.7)$ & $151(9.2)$ & $184(10.5)$ & $174(10.9)$ & $686(8.4)$ \\
\hline Next outpatient visits [n] & 3205 & 3498 & 3001 & 2644 & 1959 & 14307 \\
\hline Next hospitalizations [n] & 158 & 179 & 223 & 231 & 199 & 990 \\
\hline Deaths $[\mathrm{n}(\%)]$ & $221(16.0)$ & $244(13.7)$ & $201(12.2)$ & $177(10.1)$ & $109(6.8)$ & $952(11.7)$ \\
\hline Age at death [years] $(\mathrm{M} \pm \mathrm{SD})$ & $72.1 \pm 10.2$ & $72.2 \pm 12.2$ & $71.9 \pm 12.3$ & $73.1 \pm 11.3$ & $71.4 \pm 12.2$ & $72.2 \pm 11.6$ \\
\hline
\end{tabular}

ICD-10 - International Statistical Classification of Diseases and Related Health Problems, 10th revision.

$\mathrm{M}$ - mean; SD - standard deviation. 
Table 2. Bronchiectasis (code J47, ICD-10) in the adults aged $\geq 19$ years by defined age groups at diagnosis, Silesian voivodeship, 2006-2010

\begin{tabular}{|c|c|c|c|c|c|c|}
\hline \multirow{2}{*}{ Year } & \multicolumn{5}{|c|}{$\begin{array}{l}\text { Bronchiectasis in age groups } \\
\text { (cases) }\end{array}$} & \multirow{2}{*}{$\begin{array}{l}\text { Age of patients } \\
\text { [years] } \\
(\mathrm{M} \pm \mathrm{SD})\end{array}$} \\
\hline & $\begin{array}{c}\text { total } \\
{[\mathrm{n}]}\end{array}$ & $\begin{array}{c}\text { 19-34 years old } \\
{[\mathrm{n}(\%)]}\end{array}$ & $\begin{array}{c}\text { 35-54 years old } \\
{[\mathrm{n}(\%)]}\end{array}$ & $\begin{array}{c}\text { 55-64 years old } \\
{[\mathrm{n}(\%)]}\end{array}$ & $\begin{array}{c}\geq 65 \text { years old } \\
{[\mathrm{n}(\%)]}\end{array}$ & \\
\hline 2006 & 1382 & $151(10.9)$ & $405(29.3)$ & $335(24.2)$ & $491(35.6)$ & $56.7 \pm 15.6$ \\
\hline 2007 & 1777 & $173(9.7)$ & $542(30.5)$ & $414(23.3)$ & $648(36.5)$ & $57.3 \pm 15.4$ \\
\hline 2008 & 1647 & $122(7.4)$ & $427(25.9)$ & $421(25.6)$ & 677 (41.1) & $59.5 \pm 14.8$ \\
\hline 2009 & 1751 & $149(8.5)$ & $426(24.3)$ & $450(25.7)$ & $726(41.5)$ & $59.4 \pm 15.4$ \\
\hline 2010 & 1603 & $134(8.4)$ & $346(21.6)$ & $441(27.5)$ & $682(42.5)$ & $60.1 \pm 15.1$ \\
\hline Total & 8160 & $729(8.9)$ & $2146(26.3)$ & $2061(25.3)$ & $3224(39.5)$ & $58.6 \pm 15.3$ \\
\hline
\end{tabular}

Abbreviations as in Table 1.

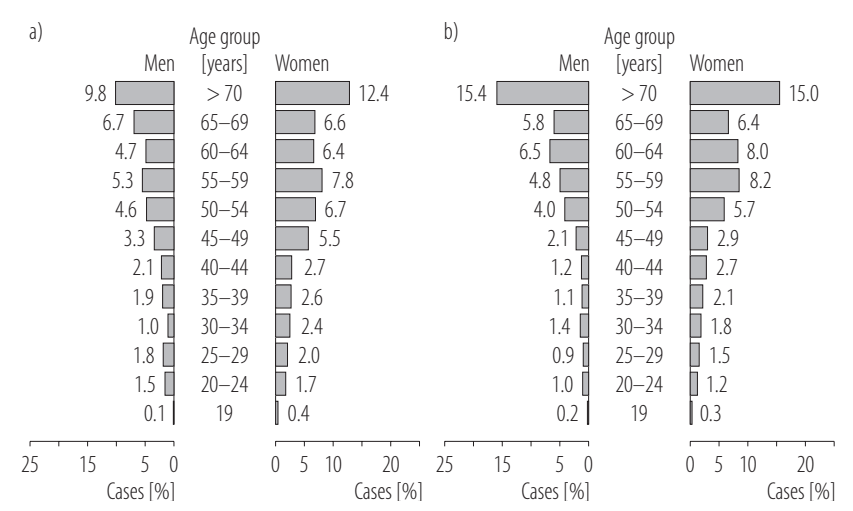

ICD-10 - as in Table 1.

Fig. 1. Adults aged $\geq 19$ years with newly diagnosed bronchiectasis (code J47, ICD-10) by gender and age groups, Silesian voivodeship: a) in 2006, and b) in 2010

was $72.2 \pm 11.6$ years. Elderly people, aged $\geq 65$ years (Table 2) constituted the largest group of patients.

Figure 1 shows changes in the age structure of the patients with bronchiectasis, according to gender, over the years 2006 and 2010, i.e., in the first and the last year of observation, respectively. The results indicated that the percentage of patients increased along with age, the largest values concerned people $>70$ years. It is worth adding that the recorded incidence was more frequent among women than in men in all the age groups.
The diseases coexisting with bronchiectasis most frequently were: respiratory diseases and cardiovascular disorders (Table 3). The number of coexisting diseases in older patients ( $\geq 65$ years) was 2 times higher than in younger people.

Table 4 shows crude and standardized incidence rates in the entire population of Silesian voivodeship. The values of crude incidence rates were different in the analyzed years and varied 36.9-47.3/100 000 inhabitants aged $\geq 19$ years. It is worth noticing that the standardized incidence was twice lower and its value was 19.9-25.1/100 000 inhabitants. Moreover, the standardized incidence rates were higher in females than in males by 3-20\% depending on the year of observation. Values of the standardized first-time hospitalization rates were 1.2-2.9/100 000 inhabitants aged $\geq 19$ years (1.1-2.3/100 000 inhabitants and 1.3$4 / 100000$ inhabitants for female and male population, respectively).

Figure 2 illustrates values of the standardized incidence of bronchiectasis averaged for the years 2006-2010 by the place of residence of patients in defined administrative units. The highest values were noted in Piekary Śląskie, the lowest values were observed in units: zawierciański and Jaworzno. 
Table 3. Registered coexisting diseases in the patients with bronchiectasis (code J47, ICD-10) in the adults aged $\geq 19$ years, Silesian voivodeship, 2006-2010

\begin{tabular}{|c|c|c|c|}
\hline \multirow{2}{*}{ Comorbidities of bronchiectasis } & \multicolumn{3}{|c|}{$\begin{array}{c}\text { Cases in age groups } \\
{[\mathrm{n}(\%)]}\end{array}$} \\
\hline & $\begin{array}{c}\text { total } \\
(\mathrm{N}=8160)\end{array}$ & $\begin{array}{c}\text { 19-65 years old } \\
(\mathrm{N}=4936)\end{array}$ & $\begin{array}{c}>65 \text { years old } \\
(\mathrm{N}=3224)\end{array}$ \\
\hline \multicolumn{4}{|l|}{ Respiratory diseases } \\
\hline total & $444(5.4)$ & $172(3.5)$ & $272(8.4)$ \\
\hline J40-J44 (chronic obstructive pulmonary disease (COPD)) & $221(2.7)$ & $81(1.6)$ & $140(4.3)$ \\
\hline J96 (respiratory failure) & $68(0.8)$ & $20(0.4)$ & $48(1.5)$ \\
\hline J18 (pneumonia) & $51(0.6)$ & $17(0.3)$ & $34(1.1)$ \\
\hline J45-J46 (asthma) & $29(0.4)$ & $23(0.5)$ & $6(0.2)$ \\
\hline J84 (other interstitial lung diseases) & $17(0.2)$ & $4(0.1)$ & $13(0.4)$ \\
\hline \multicolumn{4}{|l|}{ Cardiovascular diseases } \\
\hline total & $244(3.0)$ & $70(1.4)$ & $174(5.4)$ \\
\hline I10-I11 (hypertension) & $121(1.5)$ & $43(0.9)$ & $78(2.4)$ \\
\hline I25-I27 (heart disease) & $57(0.7)$ & $15(0.3)$ & $42(1.3)$ \\
\hline I50 (heart failure) & $27(0.3)$ & $8(0.2)$ & $19(0.6)$ \\
\hline \multicolumn{4}{|l|}{ Other diseases } \\
\hline total & $245(3.0)$ & $96(1.9)$ & $149(4.6)$ \\
\hline R04 (hemoptysis) & $52(0.6)$ & $26(0.5)$ & $26(0.8)$ \\
\hline E07-E14 (diabetes) & $34(0.4)$ & $11(0.2)$ & $23(0.7)$ \\
\hline D00-D48 (cancers) & $18(0.2)$ & $6(0.1)$ & $12(0.4)$ \\
\hline B90 (consequences of respiratory tuberculosis) & $11(0.1)$ & $6(0.1)$ & $5(0.2)$ \\
\hline Total & $933(11.4)$ & $338(6.8)$ & $595(18.5)$ \\
\hline
\end{tabular}

ICD-10 - as in Table 1.

Table 4. Crude and standardized incidence rates and first-time hospitalization due to bronchiectasis (code J47, ICD-10) in the adults aged $\geq 19$ years, Silesian voivodeship, 2006-2010

\begin{tabular}{|c|c|c|c|c|c|c|c|c|}
\hline \multirow{3}{*}{ Year } & \multicolumn{4}{|c|}{$\begin{array}{c}\text { Incidence } \\
\text { [n/100 } 000 \text { inhabitants }]\end{array}$} & \multicolumn{4}{|c|}{$\begin{array}{c}\text { First-time hospitalization } \\
\text { [n/100 } 000 \text { inhabitants] }\end{array}$} \\
\hline & \multirow{2}{*}{$\begin{array}{l}\text { crude rate } \\
\quad \text { (total) }\end{array}$} & \multicolumn{3}{|c|}{ standardized rate } & \multirow{2}{*}{$\begin{array}{l}\text { crude rate } \\
\text { (total) }\end{array}$} & \multicolumn{3}{|c|}{ standardized rate } \\
\hline & & total & women & men & & total & women & men \\
\hline 2006 & 36.9 & 19.9 & 21.4 & 18.7 & 2.0 & 1.2 & 1.1 & 1.3 \\
\hline 2007 & 47.3 & 25.1 & 27.3 & 23.4 & 2.7 & 1.6 & 1.2 & 2.2 \\
\hline 2008 & 43.8 & 22.2 & 23.0 & 22.3 & 4.0 & 2.3 & 1.8 & 3.1 \\
\hline 2009 & 46.4 & 23.7 & 26.0 & 21.7 & 4.9 & 2.9 & 2.3 & 4.0 \\
\hline 2010 & 42.4 & 21.1 & 22.2 & 20.6 & 4.6 & 2.7 & 2.1 & 3.7 \\
\hline
\end{tabular}

ICD-10 - as in Table 1. 


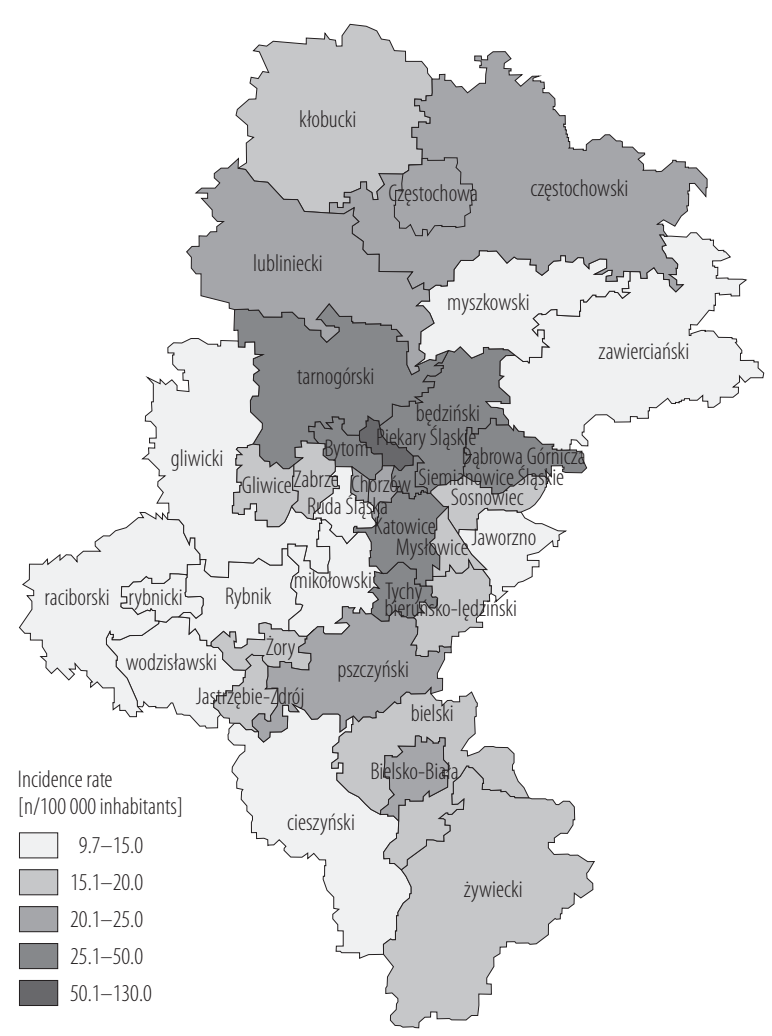

ICD-10 - as in Table 1.

Fig. 2. Standardized incidence of bronchiectasis (code J47, ICD-10) in a population aged $\geq 19$ years, Silesian voivodeship, averaged for 2006-2010

Figure 3 presents values of the standardized first-time bronchiectasis hospitalization averaged for the years 2006-2010, according to a place of residence. The highest values were noted in units: raciborski, tarnogórski and Bytom. The lowest values characterized units: mikołowski and Jastrzębie-Zdrój.

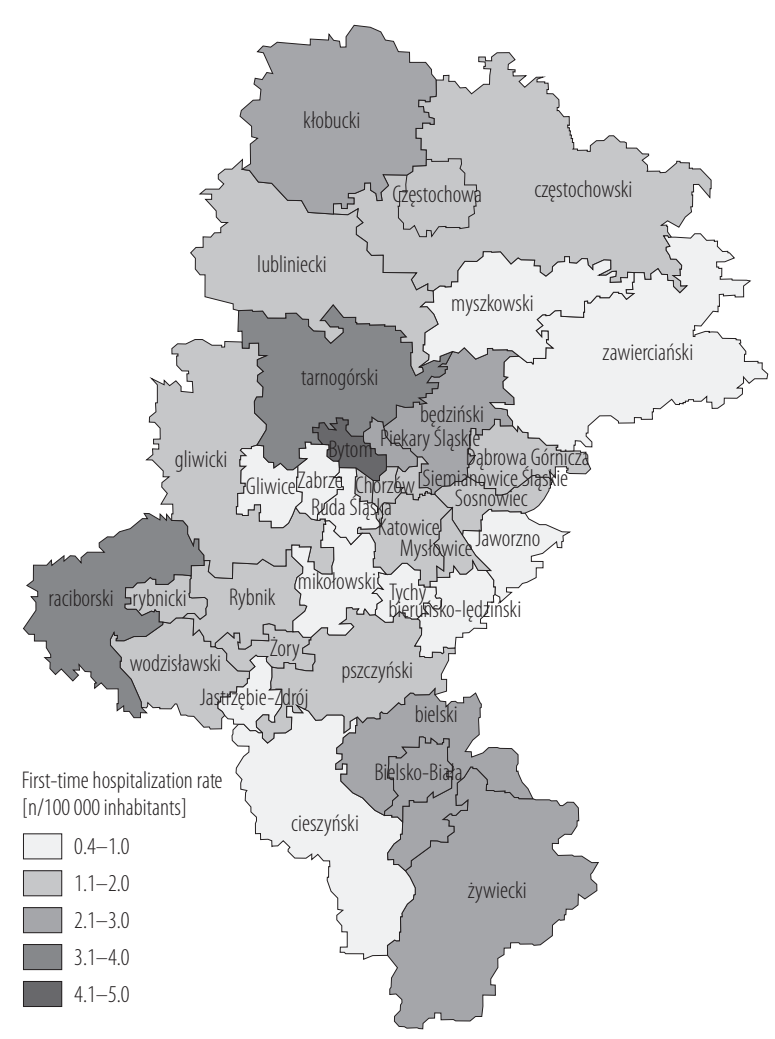

ICD-10 - as in Table 1.

Fig. 3. Standardized first-time hospitalization due to bronchiectasis (code J47, ICD-10) in a population aged $\geq 19$ years, Silesian voivodeship, averaged for 2006-2010

Spatial variability of the incidence and hospitalization of bronchiectasis were correlated with available socio-economical data and available indices of medical services (number of hospital beds per 10000 inhabitants or number of physicians). The results of correlation analyses are shown in Table 5. The only borderline

Table 5. Correlation of the averaged bronchiectasis incidence rate with selected socio-economical determinants of health, Silesian voivodeship, 2006-2010

\begin{tabular}{lcc}
\hline \multicolumn{1}{c}{ Factor } & $\mathrm{R}$ & $\mathrm{p}$ \\
\hline Unemployment rate & 0.08 & 0.66 \\
Average salary & 0.13 & 0.46 \\
No. of hospital beds per 10 000 inhabitants & 0.33 & 0.05 \\
No. of physicians & 0.11 & 0.51 \\
\hline
\end{tabular}

$\mathrm{R}$ - correlation coefficient. 
Table 6. Hospitalizations due to bronchiectasis (code J47, ICD-10) for the adults $\geq 19$ years, Silesian voivodeship, 2000-2011

\begin{tabular}{|c|c|c|c|c|c|c|}
\hline \multirow{2}{*}{ Year } & \multicolumn{3}{|c|}{ Hospitalizations } & \multicolumn{3}{|c|}{$\begin{array}{c}\text { Crude hospitalization rate } \\
\text { [n/100 } 000 \text { population] }\end{array}$} \\
\hline & $\begin{array}{c}\text { total } \\
{[\mathrm{n}]}\end{array}$ & $\begin{array}{l}\text { women } \\
{[\mathrm{n}(\%)]}\end{array}$ & $\begin{array}{c}\operatorname{men} \\
{[\mathrm{n}(\%)]}\end{array}$ & total & women & men \\
\hline 2000 & 95 & $53(55.8)$ & $42(44.2)$ & 2.0 & 2.2 & 1.8 \\
\hline 2001 & 137 & $69(50.4)$ & $68(49.6)$ & 2.9 & 2.8 & 3.0 \\
\hline 2002 & 157 & $79(50.3)$ & $78(49.7)$ & 3.3 & 3.2 & 3.4 \\
\hline 2003 & 143 & $88(61.5)$ & $55(38.5)$ & 3.0 & 3.6 & 2.4 \\
\hline 2004 & 288 & $119(41.3)$ & $169(58.7)$ & 6.1 & 4.9 & 7.4 \\
\hline 2005 & 237 & $111(46.8)$ & $126(53.2)$ & 5.1 & 4.6 & 5.6 \\
\hline 2006 & 201 & $105(52.2)$ & $96(47.8)$ & 4.3 & 4.3 & 4.3 \\
\hline 2007 & 226 & $115(50.9)$ & $111(49.1)$ & 4.9 & 4.8 & 4.9 \\
\hline 2008 & 243 & $123(50.6)$ & $120(49.4)$ & 5.2 & 5.1 & 5.4 \\
\hline 2009 & 320 & $163(50.9)$ & $157(49.1)$ & 6.9 & 6.8 & 7.0 \\
\hline 2010 & 307 & $174(56.7)$ & $133(43.3)$ & 6.6 & 7.2 & 6.0 \\
\hline 2011 & 374 & $189(50.5)$ & $185(49.5)$ & 8.1 & 7.9 & 8.3 \\
\hline
\end{tabular}

ICD-10 - as in Table 1.

significance correlation was observed for the relationship between the incidence and the number of hospital beds $(r=0.33, p=0.05)$.

Table 6 presents annual values of crude rates of hospitalization due to bronchiectasis over the years 2000 2011. In that period, the number of hospitalized patients slowly increased. The percentage of hospitalized men and women varied in the study period (2000-2011), but, in general, women were more frequently hospitalized (in 10 out of 12 years of observation). Crude rate of hospitalization was at the level of 2-8.1/100 000 inhabitants aged $\geq 19$ years $(2.2-8.1 / 100000$ inhabitants in female and 1.8-8.3/100 000 inhabitants in male population).

Figure 4 illustrates values of crude rate of hospitalizations due to bronchiectasis averaged for the years 2000-2011, according to the place of patients' residence. The highest values were recorded in Bielsko-Biała, Bytom and Piekary Śląskie. The lowest values were detected in units: bieruńsko-lędziński, pszczyński, and Jastrzębie-Zdrój.

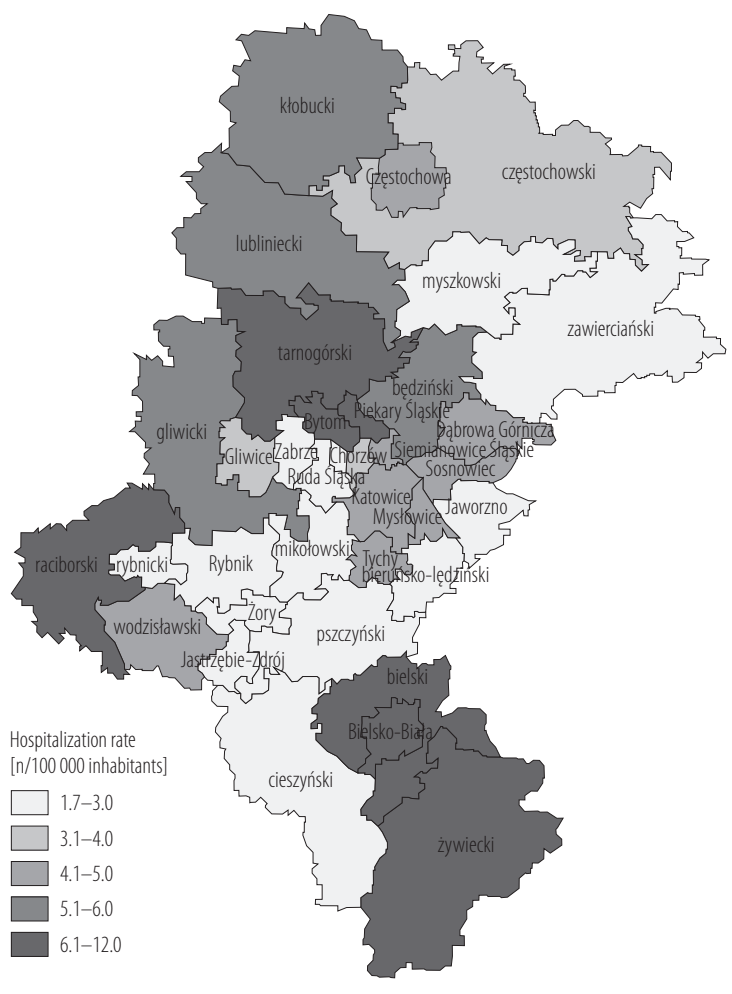

ICD-10 - as in Table 1.

Fig. 4. Hospitalization due to bronchiectasis (code J47, ICD-10) in a population aged $\geq 19$ years, Silesian voivodeship, averaged for 2006-2010 


\section{DISCUSSION}

The obtained results show a stable trend of new cases of bronchiectasis, whereas the number of first time hospitalizations increased. Bronchiectasis was a disease most frequently diagnosed in the elderly people and female population. Values of the standardized incidence were 19.925.1/100 000 inhabitants, while values of the standardized first-time hospitalization were 1.2-2.9/100 000 inhabitants. Values of crude hospitalization rates of bronchiectasis increased constantly in 2006-2010 (2-8.1/100 000 inhabitants). We showed significant spatial differences in the epidemiological situation in the considered region.

The analysis of the registered data of bronchiectasis incidence in Silesian voivodeship showed a stable epidemiological situation. In the whole study period, the disease was most frequently diagnosed among people $>70$ years. The average age of patients at the time of diagnosis was $58.6 \pm 15.3$ years. It is of interest that these were women who dominated in the group of patients with diagnosed bronchiectasis. The obtained results are similar to those observed in the USA in the years 1993-2006, in which the highest percentage of cases was observed in people aged $>65$ years, and the number of bronchiectasis hospitalizations was the highest in female population $>60$ years [7]. The impact of age is obvious given the chronic course of underlying lung disorders resulting in bronchiectasis, long time of exposure to risk factors and age related physiological changes in the respiratory system [11].

Age is also a factor contributing to the occurrence of other diseases. Among diseases accompanying bronchiectasis there are other respiratory conditions, such as: tuberculosis, pneumonia and bronchitis, pleural effusion, chronic obstructive pulmonary disease (COPD), asthma and other chronic diseases such as: congestive heart failure, coronary heart disease, kidney failure and diabetes [2]. Our results are in line with this observation. The most frequently registered comorbidities were: COPD, pneumonia, respiratory failure, haemoptysis and diabetes, ischemic heart disease and hypertension. The number of coexisting diseases was 2 times higher in the older ( $>65$ years) than in the younger patients.

In our study, the increasing number of cases of chronic obstructive pulmonary diseases along with increasing age (1.64\% among the patients aged 19-65 years and $4.34 \%$ among the patients $>65$ years) points to an etiological effect of this disorder, additionally reflecting an effect of chronic exposure to tobacco smoke [1]. The factor described in the literature as long term exposure to tobacco smoke is considered to be the main reason of the occurrence of CODP [12]. However, these literature sources emphasize the impact of toxic gases and irritants in bronchiectasis etiology [2]. Values of crude rates describing the registered new cases of bronchiectasis in Silesian voivodeship changed from $36.9 / 100000$ inhabitants to $47.3 / 100000$ inhabitants aged $>19$ years in the study period. Similar evolution was also found in the case of the standardized rates, which in the same period increased from 19.9/100 000 inhabitants to 25.1/100 000 inhabitants. Furthermore, values of the standardized incidence were higher for female population, and in the study period ranged 21.4-27.3/100 000 women aged $>19$ years. The values of rates are relatively large compared to the values listed for other European countries [5-7]. However, we cannot assess epidemiological situations (cases of bronchiectasis) in other regions of voivodeships of Poland, since the data were accessible only for the Silesia region.

In contrary to the observed incidence pattern, in the study period, the value of crude hospitalization rate of bronchiectasis constantly increased (from 2/100 000 inhabitants to 8.1/100 000 inhabitants of Silesian voivodeship). However, the lack of data on the age of the patients makes it impossible to directly standardize hospitalization due to bronchiectasis in the study region. Moreover, we observed an apparent increase in the standardized first-time 
hospitalization rates (from 1.2/100 000 inhabitants to 2.9/100 000 inhabitants in years 2006-2010).

Published data suggest that the United Kingdom, Spain, and Belgium are the European countries with a relatively high level (in excess of 6/100 000 inhabitants) of the standardized rate of hospitalization due to bronchiectasis [5]. Findings from Germany also show an increasing value of the standardized hospitalization rate due to bronchiectasis (from 1.6/100 000 inhabitants to 2.1/100 000 inhabitants) in the years 2006-2011. This rate was clearly higher in female than in male population $(2.3 / 100000$ inhabitants vs. 1.4/100 000 inhabitants, respectively), and increased along with age, showing the highest value in women aged 65-74 years (7.4/100 000 inhabitants) [8].

Published data on bronchiectasis suggest significant between-country variability of epidemiological situation, with the high standardized mortality in Hungary and in the United Kingdom (1.31/100 000 inhabitants and 1.18/100 000 inhabitants, respectively), and lower levels in Ireland and Germany (0.99/100 000 inhabitants and 0.01/100 000 inhabitants, respectively). The value in Poland is one of the lowest in the European Union (EU) and equals 0.03/100 000 population [5].

Because of the lack of data describing the cause of death in our study it was impossible to evaluate specific mortality due to bronchiectasis. The average age of the patients with bronchiectasis at the time of death was $72.2 \pm 11.6$ years. The averaged value of the standardized mortality in Germany (study period 2006-2011) was 0.03/100 000 inhabitants, $80 \%$ of deaths due to bronchiectasis occurred in the case of people older than 65 years of age [8].

We also observed significant territorial variability of the averaged values of bronchiectasis incidence and hospitalization rate in Silesian voivodeship. Our study protocol did not allow to explore this phenomenon in detail but it is of interest that the values of both rates were highest in those regions, in which the access to health service (expressed by the number of places/beds in hospitals per 10000 inhabitants) was better and the examined association was close to statistical significance (correlation coefficient $(\mathrm{R})=0.33, \mathrm{p}=0.05)$. It must be noticed, that the analysis is of ecological character, and is not sensitive to possible cause and effect dependences.

Our study has some weaknesses. First of all, we used secondary epidemiological data that may be affected by limited accuracy and completeness. However, the problem is universal for every epidemiological study using existing datasets. Secondly, it is virtually impossible to identify the onset of bronchiectasis as it is in the case of many chronic disorders. Thus, our estimation of the incidence is based on reports on newly diagnosed cases, and may be a subject of underestimation. A similar question may occur with regard to hospitalization due to the fact that these are the most severe cases of bronchiectasis that are more likely to be referred to hospitals for treatment. Nevertheless, both measures of the occurrence of bronchiectasis in our population reflect the burden of the disease and can be used for between-population comparisons.

Moreover, our study addresses the issue that is of increasing public health importance in ageing populations, and is one of the first reports providing data on epidemiology of bronchiectasis in a large Polish population. Additionally, it is the first study showing territorial variability of the incidence and hospitalization of bronchiectasis in Silesian voivodeship, based on the data recorded by the National Health Found (NFZ). The study concerns spatial and temporal characteristics of bronchiectasis in Silesian voivodeship, and one of its aims is also the reason for omission of examination and description of relations among age-groups using the incidence rates of bronchiectasis. A detailed analysis of the incidence in various age groups is not possible due to the lack of available data in the Central Statistical Office of Poland (Główny Urząd Statystyczny - GUS) databases. However, the presented results make it possible to comment on the situation in Poland compared to epidemiological situation in other countries. 


\section{CONCLUSIONS}

The results of the study show significant spatial variability of bronchiectasis cases in Silesian voivodeship, probably related to the variability in the availability of specialized medical services throughout the region. The standardized incidence rate of bronchiectasis was stable over the time, while the standardized first time hospitalization rate and crude hospitalization rate of the disease increased systematically in the study period. The values of the standardized incidence rates and crude hospitalization rates depended on age and were slightly higher in the female than in the male population.

\section{REFERENCES}

1. Wiatr E. [Shortness of breath and cough in selected lung diseases. Diagnosis, treatment, rehabilitation] [Internet]. Warszawa: 2009 [cited 2015 Apr 22]. Available from: http:// www.zus.pl/files/dpir/20091231_Dusznosc_i_kaszel_w_ wybranych_chorobach_pluc_E_Wiatr.pdf. Polish.

2. Czerniawska J, Hawryłkiewicz I, Górecka D. [A thirty-year observation of patient with bronchiectasis]. Pneumonol Alergol Pol. 2007;75(2):186-90. Polish.

3. Pierzchała W. [Respiratory diseases]. In: Duława J, editor. [Vademecum of internal medicine]. Warszawa: PZWL; 2015. p. 1292-4. Polish.

4. Piorunek T, Cofta S, Goździk J, Batura-Gabryel H. [Chronic bronchial colonization in adult patients with mucoviscidosis]. Anestezjol Ratown. 2011;5:170-5. Polish.

5. European Respiratory Society. European Lung White Book [Internet]. Sheffield: The Society [cited 2015
Apr 22]. Available from: http://www.erswhitebook.org/ chapters.

6. Aksamit TR, Schraufnagel DE. Bronchiectasis. In: Schraufnagel DE, editor. Breathing in America: Diseases, progress, and hope [Internet]. New York: American Thoracic Society; 2010. Available from: https://www.thoracic.org/patients/ patient-resources/breathing-in-america/resources/chapter4-bronchiectasis.pdf.

7. Seitz AE, Olivier KN, Adjemian J, Holland SM, Prevots DR. Trends in bronchiectasis among Medicare beneficiaries in the United State, 2000 to 2007. Chest. 2012;142(2):432-9, http://dx.doi.org/10.1378/chest.11-2209.

8. Ringshausen FC, de Roux A, Pletz MW, Hamalainen N, Welte T, Rademacher J. Bronchiectasis-associated hospitalizations in Germany, 2005-2011: A population-based study of disease burden and trends. PLoS One. 2013;8(8):e71109, http://dx.doi.org/10.1371/journal. pone. 0071109 .

9. [The Act of 10 April 2003 to amend the Act on general insurance in the National Health Fund. J Laws. 2003, No. 73, item 660]. Polish.

10. Local data bank [Internet]. Warszawa: Główny Urząd Statystyczny; 1995-2015 [cited 2015 Apr 22]. Available from: https://bdl.stat.gov.pl/BDL/metadane/teryt/lista.

11. Lubiński W. [Chronic obstructive pulmonary disease in the elderly]. Geriatria. 2008;2:151-6. Polish.

12. Mannino DM, Buist AS. Global burden of COPD: Risk factors, prevalence, and future trends. Lancet. 2007;370: 765-73, http://dx.doi.org/10.1016/S0140-6736(07)61380-4.

This work is available in Open Access model and licensed under a Creative Commons Attribution-NonCommercial 3.0 Poland License - http://creativecommons.org/ licenses/by-nc/3.0/pl/deed.en. 